\title{
Risk of hospitalization in patients with diabetes mellitus who have solid-organ malignancy
}

Background: To determine the relationship between diabetes mellitus (DM) and hospitalization risk in patients with solid-organ malignancies, hospitalized patients with a new solid-organ malignancy and DM were retrospectively analyzed. Results: The presence of DM conferred a $72 \%$ greater chance (odds ratio [OR]: $1.72,95 \% \mathrm{Cl}$ : $1.46-2.04 ; p<0.01$ ) of requiring any hospitalization and increased the chances of having multiple admissions by $84 \%$ (OR: $1.84,95 \% \mathrm{Cl}: 1.53-2.21 ; \mathrm{p}<0.01)$. Additionally, the presence of DM increased the duration of hospital stay by 0.57 days $(p<0.01)$. Conclusion: The presence of DM in patients with solid-organ malignancies increases the risk of any hospitalization, multiple hospitalizations and length of hospital stay.

Lay abstract: To determine the relationship between diabetes mellitus (DM) and hospitalization risk in patients with solid-organ malignancies, hospitalized patients with a new solid-organ malignancy and DM were retrospectively analyzed. The study found that the presence of DM conferred a $72 \%$ greater chance of requiring any hospitalization and increased the chances of having multiple admissions by $84 \%$. Additionally, the presence of DM increased the duration of hospital stay by more than half a day. The study concluded that the presence of DM in patients with solid-organ malignancies increases the risk of any hospitalization, multiple hospitalizations and duration of hospital stay.

First draft submitted: 15 March 2016; Accepted for publication: 29 April 2016; Published online: 15 July 2016

Keywords: diabetes mellitus $\bullet$ hospital stay $\bullet$ hospitalization $\bullet$ risk $\bullet$ solid-organ malignancy

The presence of diabetes mellitus (DM) is associated with a greater risk of both onset and mortality in many types of solid-organ malignancies, including breast, colorectal, endometrial, pancreatic, liver and bladder cancers [1-7]. Hyperglycemia, even among patients without DM, has also been linked to increased cancer mortality and to more aggressive clinical behavior of the cancer [810]. Obesity, diet and hyperinsulinemia are some of the identified shared risk factors for DM and certain types of cancers $[2,5,6]$.

For many types of solid-organ cancers, hospitalizations pose a considerable burden and contribute to the high costs of these diagno- ses [11-15]. Similarly, hospitalizations account for $40 \%$ of all DM-related costs [16]. Additionally, DM is associated with greater odds of requiring a hospitalization, a higher risk of multiple hospitalizations and longer hospital stays than in the non-DM population [1721]. However, the interactions among DM, patients with solid-organ malignancy and the risk of hospitalization have never been established, and data on the topic are lacking. These interrelationships should be explored as a prelude to future investigations focused on economic burden or modifiable factors that could be targeted to reduce hospital risk in patients with these dual diagnoses.
Nina J Karlin*,1 Heidi E Kosiorek², Janna C Castro ${ }^{3}$ \& Curtiss B Cook ${ }^{4}$ 'Division of Hematology and Medical Oncology, Mayo Clinic, Scottsdale, AZ, USA

2Division of Biostatistics, Mayo Clinic, Scottsdale, AZ, USA

${ }^{3}$ Department of Information Technology, Mayo Clinic Hospital, Phoenix, AZ, USA ${ }^{4}$ Division of Endocrinology and Division of Preventive, Occupational, and Aerospace Medicine, Mayo Clinic, Scottsdale, AZ, USA

*Author for correspondence:

karlin.nina@mayo.edu 
The authors have analyzed institutional data to examine the interactions among DM, glycemic control and risk of mortality among patients with solidorgan malignancies [22,23]. A recent report assessed the status of glycemic control among hospitalized patients with coexisting cancer and DM [24]. However, no studies have described the hospital characteristics of patients with cancer who have DM or how DM affects the risk of hospitalizations among patients with solid-organ malignancies. Hence, a retrospective analysis of patients who had cancer with and without DM was conducted to determine the association between DM and risk of hospitalization, the need for multiple hospitalizations and duration of hospital stay.

\section{Methods}

\section{Description of institutional cancer registry}

The authors' institution is an academic facility located in southwestern USA. The cancer registry maintained by the authors' institution is an information system designed for the collection, management, analysis and dissemination of data on persons with the diagnosis of malignant or neoplastic disease seen at the facility. When a patient receives the diagnosis of cancer, information obtained from the medical record becomes part of the registry. Certified cancer registrars enter and abstract information and enter it into the database. The registry contains up to 350 items pertinent to each case, including demographics, diagnosis, year of diagnosis and recurrence data.

\section{Case selection}

The study was approved by the Mayo Clinic Institutional Review Board (protocol ID: 12-008284) and included patients from the authors' academic institution. Patients with a new solid-organ malignancy diagnosed from 1 January 2009, through 31 December 2011, were identified in the institutional cancer registry, as previously described [22-24]. Patients with more than one primary malignancy, hematologic malignancies or skin cancers were excluded. This data set was linked to electronic health records to determine which patients had a diagnosis of DM at the time of the cancer diagnosis. This file was then cross-referenced against hospital discharge data to determine who had evidence of hospitalizations within the authors' facility from 1 January 2010, through 31 December 2013 (the analytic period). The later dates were included to ensure capture of all hospitalizations within the authors' institution over a period of time for which data were available at the time of the analysis. Hemoglobin $A_{1 c}\left(H_{b} A_{1 c}\right)$ values obtained during the inpatient stay were extracted from the laboratory infor- mation system. Measurement of $\mathrm{HbA}_{1 \mathrm{c}}$ for inpatients with DM is part of the facility's guidelines for management of these patients. For patients who were not hospitalized, $\mathrm{HbA}_{1 \mathrm{c}}$ values would not have been available because their outpatient DM care likely would have been obtained elsewhere.

\section{Statistical analysis}

Descriptive statistics were used to describe the characteristics of the patients, categorized according to DM diagnosis. Patient-level characteristics were compared between groups by $\mathrm{F}$ test for continuous variables and $\chi^{2}$ test for frequency data. Generalized estimating equations (GEEs) were used to account for the correlation between the repeated measurements within a patient. Therefore, multivariable GEE models were used to examine the association between hospitalization risk and DM while controlling for age, cancer type, race or ethnicity and sex. A logistic model was also used to examine the risk of having multiple admissions, and the relationship between DM and duration of hospital stay was assessed with a linear GEE model. A patient was considered to have multiple admissions if two or more hospitalizations occurred during the analytic period. Sequential models were tested in a backward elimination fashion for each outcome variable to determine the best fit, and those variables that were not significant were removed from the final model.

The relationships of the $\mathrm{HbA}_{1 \mathrm{c}}$ level with the risk of needing multiple hospitalizations and with duration of stay were evaluated. The authors' institution has recommended that $\mathrm{HbA}_{1 \mathrm{c}}$ values be determined when appropriate at admission. Because $\mathrm{HbA}_{1 \mathrm{c}}$ levels were available only for patients who were inpatients in this data set, the analysis was restricted to the subset of patients with DM who were hospitalized. All statistical analysis was conducted with SAS 9.3 (SAS Institute Inc). All tests were two-sided, and statistical significance was set at $\mathrm{p}<0.05$.

\section{Results}

\section{Patient characteristics}

Of the 4620 patients identified with solid-organ malignancies (Table 1), 732 (15.8\%) had a coexisting DM diagnosis and 3888 (84.2\%) did not. Among the 4620 patients, 2378 (51.5\%) had at least one hospitalization, and $2242(48.5 \%)$ did not have a hospitalization documented in the system. Of the 2378 patients requiring a hospitalization, 1406 (59.1\%) had only one admission, and the remaining 972 (40.9\%) of patients had more than one admission during the analytic period.

On examination of demographic differences, patients with DM were slightly but significantly older 
Table 1. Characteristics of patients with solid-organ malignancies according to status of diabetes mellitus.

\begin{tabular}{|c|c|c|c|c|}
\hline \multirow[t]{2}{*}{ Characteristic } & \multicolumn{2}{|c|}{ Diabetes mellitus } & \multirow[t]{2}{*}{ Total $(n=4620)$} & \multirow[t]{2}{*}{ p-value } \\
\hline & No $(n=3888)$ & Yes $(n=732)$ & & \\
\hline Age, mean (SD), years & $65.6(13.3)$ & $68.4(10.7)$ & $66.0(12.9)$ & $<0.01$ \\
\hline $\begin{array}{l}\text { Time from cancer diagnosis, mean } \\
\left(\text { SD), years }{ }^{\dagger}\right.\end{array}$ & $1.65(1.12)$ & $1.57(1.10)$ & $1.64(1.12)$ & 0.06 \\
\hline Sex: & & & & $<0.01$ \\
\hline - Female & 1527 (39.3) & $238(32.5)$ & 1765 (38.2) & \\
\hline - Male & $2361(60.7)$ & $494(67.5)$ & $2855(61.8)$ & \\
\hline Race: & & & & 0.26 \\
\hline - Nonwhite & $263(6.9)$ & $56(8.0)$ & $319(7.0)$ & \\
\hline - White & 3567 (93.1) & $640(92.0)$ & 4207 (93.0) & \\
\hline Missing & 58 & 35 & 94 & \\
\hline Cancer type: & & & & $<0.01$ \\
\hline - Bladder & $138(3.5)$ & $34(4.6)$ & $172(3.7)$ & \\
\hline - Breast & $423(10.9)$ & $47(6.4)$ & $470(10.2)$ & \\
\hline - Colorectal & $252(6.5)$ & $42(5.7)$ & $294(6.4)$ & \\
\hline - Gynecologic & $170(4.4)$ & $33(4.5)$ & $203(4.4)$ & \\
\hline - Kidney & $207(5.3)$ & $65(8.9)$ & $272(5.9)$ & \\
\hline - Liver & $89(2.3)$ & $59(8.1)$ & $148(3.2)$ & \\
\hline - Lung & $442(11.4)$ & $76(10.4)$ & $518(11.2)$ & \\
\hline - Other & $1062(27.3)$ & $201(27.5)$ & $1263(27.3)$ & \\
\hline - Pancreas & & $61(8.3)$ & $235(5.1)$ & \\
\hline - Prostate & $174(4.5)$ & $114(15.6)$ & $1045(22.6)$ & \\
\hline \multicolumn{5}{|l|}{ Hospitalized: } \\
\hline$-\mathrm{No}$ & $1968(50.6)$ & $274(37.4)$ & $2242(48.5)$ & \\
\hline- Yes & $1920(49.4)$ & $458(62.6)$ & $2378(51.5)$ & \\
\hline No. of hospitalizations: & & & & $<0.01$ \\
\hline-1 & $1,184(61.7)$ & $222(48.5)$ & $1,406(59.1)$ & \\
\hline-2 & $382(19.9)$ & $114(24.9)$ & $496(20.9)$ & \\
\hline-3 & $160(8.3)$ & $49(10.7)$ & $209(8.8)$ & \\
\hline-4 & $194(10.1)$ & $73(15.9)$ & $267(11.2)$ & \\
\hline $\begin{array}{l}\text { Duration of stay (hospitalized } \\
\text { patients), mean (SD), days }\end{array}$ & $5.6(5.2)$ & $6.1(5.5)$ & $5.7(5.3)$ & 0.003 \\
\hline
\end{tabular}

than patients without DM, and more patients with DM were men (Table 1). No differences in race or ethnicity or in the duration of cancer diagnosis were detected. The distribution of solid-organ malignancies included in the analysis was different between the two groups. For instance, breast and prostate cancers were more common among patients without DM, whereas renal, hepatic and pancreatic malignancies occurred more frequently among patients with DM.
Differences were found in the hospital data (Table 1). Hospitalizations were significantly more frequent among patients with DM than those without DM. Patients with DM also experienced more multiple hospitalizations than those without DM. Also, patients with DM remained in the hospital on average a half day longer than patients without coexisting DM. Total amount of follow-up time from cancer diagnosis date until last contact date or death was similar between patients 
with DM (15.5 months) and those without DM (16.7 months; $\mathrm{p}=.29)$.

\section{DM \& hospitalization risk among patients with cancer}

After adjustment for other variables, GEE models predicting hospitalization risk showed that DM conferred a $72 \%$ greater chance of requiring a hospitalization (Table 2). In contrast, for every 5-year increase in age, the odds of requiring a hospitalization decreased by $5 \%$. When compared with patients who had prostate cancer, patients with some solid-organ malignancies (e.g., bladder, colorectal, kidney) had greater odds of requiring a hospitalization. Coexisting DM also increased the chances of having multiple admissions by $84 \%$ (Table 3). White race or ethnicity also increased the odds, and all cancer types evaluated were associated with higher odds of multiple hospitalizations than prostate cancer.

\section{DM \& hospital duration of stay}

Linear GEE models were used to assess the association between duration of hospital stay and DM (Table 4). After adjustment for cancer type and sex, the presence of DM significantly increased the duration of stay by 0.57 day. All cancer types included in the analysis were associated with longer durations of stay when compared with prostate cancer. Also, men were in the hospital nearly a half day longer than women.

$\mathrm{HbA}_{1 c}$ level, multiple hospitalizations \& duration of stay

Among the subset of DM patients who were hospitalized $(n=458)$, the mean $(S D) \mathrm{HbA}_{1 c}$ value was 6.8
(1.3)\%. After adjustment for cancer type, age, sex and race or ethnicity, there was no correlation between $\mathrm{HbA}_{1 \mathrm{c}}$ level and the need for multiple admissions (odds ratio [OR]: 0.95; 95\% CI: 0.77-1.17; $\mathrm{p}=0.63$ ). In addition, there was no relationship between $\mathrm{HbA}_{1 \mathrm{c}}$ level and duration of stay ( $\beta$ estimate $=-0.21 ; 95 \% \mathrm{CI}$ : $-0.75-0.32 ; \mathrm{p}=0.45)$.

\section{Discussion}

DM is associated with a greater chance of a patient being hospitalized [17-20]. DM and cancer are high-profile topics that individually garner much attention in the literature. DM and solid-organ malignancies place a high burden on the health care system, and hospitalizations compose a substantial part of this burden for both categories of patients. However, the interactions among DM, cancer and risk of hospitalization have not been specifically examined.

Analysis of this institutional dataset indicates that patients with solid-organ malignancies who had DM had a substantially increased risk of being hospitalized. Moreover, patients who had cancer with coexisting DM had more hospitalizations and remained in the hospital for slightly longer than their non-DM counterparts. The reasons for this greater risk cannot be ascertained from this dataset. Possible factors are the number and severity of DM complications and the presence of other comorbidities commonly found with DM (e.g., cardiovascular disease, hypertension). Additional study is required to determine what specific characteristics of patients with DM may predispose them to needing a hospital admission compared with the non-DM population with solid-organ malignancies.

Table 2. Generalized estimating equation models predicting hospitalization risk.

\begin{tabular}{|llll|}
\hline Factor & Odds ratio & $95 \% \mathrm{Cl}$ & p-value \\
\hline Diabetes: yes vs no & 1.72 & $1.46-2.04$ & $<0.01$ \\
\hline Age (per 5-year increase) & 0.95 & $0.93-0.98$ & $<0.01$ \\
\hline Cancer type $^{\dagger}$ & & & $<0.01$ \\
\hline Bladder & 2.29 & $1.63-3.22$ & 0.79 \\
\hline Breast & 0.97 & $0.78-1.21$ & $<0.01$ \\
\hline Colorectal & 1.74 & $1.33-2.27$ & 0.30 \\
\hline Gynecologic & 1.18 & $0.87-1.60$ & 0.02 \\
\hline Kidney & 1.39 & $1.06-1.82$ & 0.12 \\
\hline Liver & 1.32 & $1.07-1.88$ & 0.16 \\
\hline Lung & 1.16 & $0.94-1.44$ & 0.02 \\
\hline Other & 1.23 & $1.04-1.45$ & 0.48 \\
\hline $\begin{array}{l}\text { Pancreas } \\
\text { Sex and race did not contribute and were removed from the final model. }\end{array}$ \\
tReferent: prostate cancer.
\end{tabular}


Table 3. Generalized estimating equation models predicting risk of multiple hospitalizations.

\begin{tabular}{|llll|}
\hline Factor & Odds ratio & $95 \% \mathrm{Cl}$ & p-value \\
\hline Diabetes: yes vs no & 1.84 & $1.53-2.21$ & $<0.01$ \\
\hline White vs nonwhite $^{\prime}$ & 1.55 & $1.12-2.13$ & $<0.01$ \\
\hline Cancer type $^{\dagger}$ & & & $<0.01$ \\
\hline Bladder & 4.67 & $3.18-6.86$ & $<0.01$ \\
\hline Breast & 2.80 & $2.06-3.80$ & $<0.01$ \\
\hline Colorectal & 4.74 & $3.42-6.59$ & $<0.01$ \\
\hline Gynecologic & 3.40 & $2.31-5.00$ & $<0.01$ \\
\hline Kidney & 2.45 & $1.70-3.54$ & $<0.01$ \\
\hline Liver & 4.44 & $2.93-6.72$ & $<0.01$ \\
\hline Lung & 2.42 & $1.79-3.28$ & $<0.01$ \\
\hline Other & 2.91 & $2.27-3.74$ & $<0.01$ \\
\hline Pancreas & 3.03 & $2.09-4.37$ & \\
\hline $\begin{array}{l}\text { Age and sex did not contribute and were removed from the final model. } \\
\text { tReferent: prostate cancer. }\end{array}$ & & \\
\hline
\end{tabular}

The reported association between glycemic control and risk of multiple hospitalizations among patients with DM is inconsistent [21]. In one study, the $\mathrm{HbA}_{1 \mathrm{c}}$ level was significantly correlated with risk of readmissions between 30 and 90 days among patients with congestive heart failure [25]. In our analysis, the $\mathrm{HbA}_{1 \mathrm{c}}$ level was not found to be significantly associated with more frequent hospitalizations among patients with DM who were hospitalized at least once. If future studies confirm this finding, then intensified outpatient treatment of hyperglycemia may not be of benefit in terms of decreasing the risk of multiple admissions among patients with cancer, and a search for other modifiable risk factors would have to be undertaken.
However, this finding by no means negates the need to optimize glycemic control in patients with cancer as it would with patients with other comorbidities. For instance, patients with newly diagnosed solidorgan malignancies may require surgery as first-line treatment, and optimizing glycemic control before and after the episode of surgical care can improve outcomes [26].

The increased risk of hospitalization, multiple hospitalizations and longer duration of stay imposed by DM on patients with cancer has potentially significant economic implications. When considered separately, hospitalizations represent a large part of the costs to the healthcare system for patients with DM

\section{Table 4. Generalized estimating equation models predicting duration of hospital stay.}

\begin{tabular}{|llll|}
\hline Factor & $\beta$ estimate & $95 \% \mathrm{Cl}$ & p-value \\
\hline Diabetes: yes vs no & 0.57 & $0.16-0.97$ & $<0.01$ \\
\hline Male vs female & 0.50 & $0.07-0.93$ & 0.02 \\
\hline Cancer type $^{\dagger}$ & & & $<0.01$ \\
\hline Bladder & 3.63 & $2.84-4.42$ & $<0.01$ \\
\hline Breast & 1.35 & $0.75-1.94$ & $<0.01$ \\
\hline Colorectal & 3.15 & $2.41-3.90$ & $<0.01$ \\
\hline Gynecologic & 2.37 & $1.54-3.19$ & $<0.01$ \\
\hline Kidney & 1.16 & $0.66-1.65$ & $<0.01$ \\
\hline Liver & 2.36 & $1.31-3.40$ & $<0.01$ \\
\hline Lung & 2.63 & $2.07-3.18$ & $<0.01$ \\
\hline Other & 2.77 & $2.33-3.22$ & $<0.01$ \\
\hline Pancreas & 3.38 & $2.57-4.18$ & \\
\hline $\begin{array}{l}\text { Age and race did not contribute and were removed from the final model. } \\
\text { Referent: prostate cancer. }\end{array}$ & & \\
\hline
\end{tabular}


and cancer [11-16]. When the two diseases coexist, the economic impact is likely to be magnified above that of either alone, and because no data exist, the topic requires further discussion and analysis.

This analysis has some limitations. It is from a single institution and results cannot be generalized to patients in other facilities. The use of the institutional cancer registry as the primary data source did not allow for inclusion of some patient-level variables, such as presence of DM-related complications or the duration of DM, which are not part of the registry but could be important predictors of hospitalization risk. Additionally, electronic data do not accurately collect the cause of DM (e.g., Type 1 vs Type 2). Although there is no reason to suspect that the cause of DM changes hospitalization risk, this variable should be considered in future analyses. Chart review on a smaller sample size to collect more characteristics, as was recently done for patients who had breast cancer and DM [23], would allow a more indepth case-control analysis to be performed. Moreover, no information is available on whether patients may have been hospitalized outside the institution. Also, the lack of $\mathrm{HbA}_{1 \mathrm{c}}$ values in patients with $\mathrm{DM}$ who were not hospitalized did not permit an analysis of correlation between $\mathrm{HbA}_{1 \mathrm{c}}$ levels and risk of any inpatient stay.

\section{Conclusion}

Limitations aside, to the authors' knowledge this is the first analysis that has specifically examined the association between DM and the risk of any hospitalization, multiple hospitalizations and duration of hospital stay among patients with cancer. DM coexisting with solid-organ malignancies was significantly associated with all three measures. The economic implications of both diagnoses together must be studied, and a better understanding of why patients with DM and cancer have these higher risks should be explored so that mitigating strategies can be developed. Further study of the DM-cancer-hospitalization connection is needed.

\section{Future perspective}

Currently, there is a dearth of research in the literature about patients with cancer and DM who are hospitalized. In this study, we found that patients with DM who have solid-organ malignancies have an increased risk of hospitalization and duration of hospital stay. Determination of DM-related factors contributing to increased risk of hospitalization in these patients is an ideal next step for future research. This knowledge will help to implement appropriate preventive measures to decrease risk of hospitalization and duration of hospital stay in patients with DM who have solid-organ malignancies.

\section{Financial \& competing interests disclosure}

The authors have no relevant affiliations or financial involvement with any organization or entity with a financial interest in or financial conflict with the subject matter or materials discussed in the manuscript. This includes employment, consultancies, honoraria, stock ownership or options, expert testimony, grants or patents received or pending, or royalties.

No writing assistance was utilized in the production of this manuscript.

\section{Ethical disclosure}

For studies involving data relating to human or animal experimental investigations, appropriate institutional review board approval has been obtained and is described within the article (for those investigators who do not have formal ethics review committees, the principles outlined in the Declaration of Helsinki have been followed).

\section{Open access}

This work is licensed under the Creative Commons Attribution 4.0 License. To view a copy of this license, visit http://creativecommons.org/licenses/by/4.0/

\section{Executive summary}

- Diabetes mellitus (DM) coexisting with solid-organ malignancies is associated with risk of hospitalization and multiple hospitalizations.

- DM coexisting with solid-organ malignancies is associated with longer duration of hospital stay.

- Hemoglobin A1c level was not associated multiple hospitalizations or length of stay.

- The economic implications of both diagnoses together must be studied.

- A better understanding of why patients with DM and cancer have these higher risks should be explored so that mitigating strategies can be developed.

- Possible factors for the findings are the number and severity of DM complications and the presence of other comorbidities that are commonly found with DM (e.g., cardiovascular disease, hypertension).

- The findings have potentially significant economic implications: hospitalizations, considered separately, represent a large part of the costs to the health care system for patients with DM and cancer.

- When DM and cancer coexist, the economic impact is likely to be magnified above that of either alone. 


\section{References}

Papers of special note have been highlighted as:

- of interest; $\bullet \bullet$ of considerable interest

1 Barone BB, Yeh HC, Snyder CF et al. Long-term all-cause mortality in cancer patients with preexisting diabetes mellitus: a systematic review and meta-analysis. JAMA 300(23), 2754-2764 (2008).

2 Vigneri P, Frasca F, Sciacca L, Pandini G, Vigneri R. Diabetes and cancer. Endocr. Relat. Cancer 16(4), 1103-1123 (2009).

3 Ogunleye AA, Ogston SA, Morris AD, Evans JM. A cohort study of the risk of cancer associated with Type 2 diabetes. Br. J. Cancer 101(7), 1199-1201 (2009).

4 Barone BB, Yeh HC, Snyder CF et al. Postoperative mortality in cancer patients with preexisting diabetes: systematic review and meta-analysis. Diabetes Care 33(4), 931-939 (2010).

5 Giovannucci E, Harlan DM, Archer MC et al. Diabetes and cancer: a consensus report. Diabetes Care 33(7), 1674-1685 (2010).

-• This is a review of diabetes and cancer with respect to prognosis, common risk factors, possible biologic links and whether diabetes treatment affects cancer prognosis.

6 Handelsman Y, Leroith D, Bloomgarden ZT et al. Diabetes and cancer: an AACE/ACE consensus statement. Endocr. Pract. 19(4), 675-693, Erratum in: Endocr. Pract. 19 (5), 899 (2013).

7 Zelenko Z, Gallagher EJ. Diabetes and cancer. Endocrinol. Metab. Clin. North Am. 43(1), 167-185 (2014).

8 Siddiqui AA, Spechler SJ, Huerta S, Dredar S, Little BB, Cryer B. Elevated HbAlc is an independent predictor of aggressive clinical behavior in patients with colorectal cancer: a case-control study. Dig. Dis. Sci. 53(9), 2486-2494 (2008).

9 Seshasai SR, Kaptoge S, Thompson A et al. Emerging Risk Factors Collaboration. Diabetes mellitus, fasting glucose, and risk of cause-specific death. N. Engl. J. Med. 364(9), 829-841, Erratum in: N. Engl. J. Med. 364 (13), 1281 (2011).

- In addition to other diseases, diabetes was found to be associated with substantial premature death from several cancers, independent of several major risk factors.

10 Luo J, Chen YJ, Chang LJ. Fasting blood glucose level and prognosis in non-small cell lung cancer (NSCLC) patients. Lung Cancer 76(2), 242-247 (2012).

11 Barron JJ, Quimbo R, Nikam PT, Amonkar MM. Assessing the economic burden of breast cancer in a US managed care population. Breast Cancer Res. Treat. 109(2), 367-377 (2008).

12 Warren JL, Yabroff KR, Meekins A, Topor M, Lamont EB, Brown ML. Evaluation of trends in the cost of initial cancer treatment. J. Natl Cancer Inst. 100 (12), 888-897 (2008).

13 Insinga RP, Ye X, Singhal PK, Carides GW. Healthcare resource use and costs associated with cervical, vaginal and vulvar cancers in a large U.S. health plan. Gynecol. Oncol. 111(2), 188-196 (2008).

14 O'Neill CB, Atoria CL, O'Reilly EM, LaFemina J, Henman $\mathrm{MC}$, Elkin EB. Costs and trends in pancreatic cancer treatment. Cancer 118(20), 5132-5139 (2012).
15 Mossanen M, Gore JL. The burden of bladder cancer care: direct and indirect costs. Curr. Opin. Urol. 24(5), 487-491 (2014).

- There are substantial financial costs associated with nonmuscle invasive bladder cancer.

16 American Diabetes Association. Economic costs of diabetes in the U.S. in 2012. Diabetes Care 36(4), 1033-1046 (2013).

17 Rosenthal MJ, Fajardo M, Gilmore S, Morley JE, Naliboff BD. Hospitalization and mortality of diabetes in older adults: a 3 year prospective study. Diabetes Care 21(2), 231-235 (1998).

18 Donnan PT, Leese GP, Morris AD. Diabetes Audit and Research in Tayside, Scotland/Medicine Monitoring Unit Collaboration. Hospitalizations for people with Type 1 and Type 2 diabetes compared with the nondiabetic population of Tayside, Scotland: a retrospective cohort study of resource use. Diabetes Care 23(12), 1774-1779 (2000).

19 Jiang HJ, Stryer D, Friedman B, Andrews R. Multiple hospitalizations for patients with diabetes. Diabetes Care 26(5), 1421-1426 (2003).

-. Patients with diabetes have multiple hospitalizations, and there are opportunities to decrease this number.

20 Bo S, Ciccone G, Grassi G et al. Patients with Type 2 diabetes had higher rates of hospitalization than the general population. J. Clin. Epidemiol. 57(11), 1196-1201 (2004).

21 Dungan KM. The effect of diabetes on hospital readmissions. J. Diabetes Sci. Technol. 6(5), 1045-1052 (2012).

- Diabetes is associated with increased hospital readmission.

22 Karlin NJ, Dueck AC, Cook CB. Cancer with diabetes: prevalence, metabolic control, and survival in an academic oncology practice. Endocr. Pract. 18(6), 898-905 (2012).

23 Karlin NJ, Dueck AC, Nagi Reddy SK, Verona PM, Cook CB. Implications of breast cancer with diabetes mellitus on patient outcomes and care. Diabetes Manag. 4(5), 411-419 (2014).

24 Karlin NJ, Cheng M-R, Castro JC, Cook CB. Hyperglycemia among hospitalized cancer patients with coexisting diabetes mellitus. Diabetes Manag. 5(6), 441-448 (2015).

- Inpatient hyperglycemia management is not associated with type of solid-organ malignancy.

25 Dungan KM, Osei K, Nagaraja HN, Schuster DP, Binkley P. Relationship between glycemic control and readmission rates in patients hospitalized with congestive heart failure during implementation of hospital-wide initiatives. Endocr. Pract. 16(6), 945-951 (2010).

26 Coan KE, Apsey HA, Schlinkert RT, Stearns JD, Cook CB. Managing diabetes mellitus in the surgical patient. Diabetes Manag. 4(6), 515-526 (2014). 